\title{
Probabilistic Risk Assessment Using the Fuzzy Fault Tree Analysis Based on Two Types of Failure Possibility Distributions in Process Industries
}

\author{
Abbas Bekbaki ${ }^{1}$, Nader Nebhani ${ }^{2}$, Bagher Anvaripour ${ }^{2, *}$, Gholam Abbas Shirali ${ }^{3}$ \\ ${ }^{1}$ MS Student of Chemical Engineering (Health, Safety, and Environment), Department of Safety and Technical Protection \\ Engineering, Abadan Faculty of Petroleum, Petroleum University of Technology, Abadan, Iran \\ ${ }^{2}$ Associate Professor, Department of Safety and Technical Protection Engineering, Abadan Faculty of Petroleum, Petroleum \\ University of Technology, Abadan, Iran \\ ${ }^{3}$ Associate Professor, Department of Occupational Health Engineering, Faculty of Health, Ahwaz Jundishapur University of \\ Medical Sciences, Ahwaz, Iran \\ * Corresponding Author: Bagher Anvaripour, Department of Safety and Technical Protection Engineering, Abadan Faculty \\ of Petroleum, Petroleum University of Technology, Abadan, Iran.Email: anvaripour@put.ac.ir
}

Received: 25/04/2017

Accepted: 20/09/2017

\section{How to Cite this Article:} Bekbaki A, Nebhani N, Anvaripour B, Shirali GA. Probabilistic Risk Assessment Using the Fuzzy Fault Tree Analysis Based on Two Types of Failure Possibility Distributions in Process Industries. J Occup Hyg Eng. 2017; 4(2): 41-52. DOI: 10.18869/acadpub.johe.4.2.41

\section{Abstract}

Background and Objective: Probabilistic risk assessment through fault tree analysis is an effective tool to estimate the probability of hazardous event occurrence in chemical process industries. The probability of failure occurrence for basic events is not often available in process industries. The aim of this study was to calculate the basic event failure occurrence probability when these events have no precise failure data.

Materials and Methods: In this study, the proposed risk assessment framework was based on two fuzzy-based approaches, including five and six scales. Firstly, the fault tree diagram was constructed using the risk identification methods. Subsequently, the failure occurrence probability of the basic events were calculated by applying the two types of failure possibility distributions. Finally, the critical minimal cut sets were ranked using the importance measure analysis.

Results: According to the results, the failure occurrence probabilities calculated by the five-scale and six-scale approaches for the 32 basic events were closed to each other. The occurrence probability of the top event calculated by the five-scale and six-scale approaches were 3.64E-04 and 4.76E-04 per year, respectively. After ranking the minimal cut sets based on their calculated importance measures, the process failures were determined as the critical causes of top event.

Conclusion: As the findings indicated, the fuzzy-based approach seems to be a good alternative for the conventional Fault tree analysis approach for dealing with the basic events, which have no failure rate data for obtaining the failure occurrence probabilities. This study confirmed the consistency of fuzzy-based approach for the assessment of the basic event failure occurrence probabilities.

Keywords: Expert Judgment; Fuzzy Logic; Failure Occurrence Probability; Failure Possibility; Fuzzy Fault Tree Analysis 
dof: $10.18869 /$ acadpub.johe.4.2.41

\section{ارزيابى ريسك احتمالى به روش آناليز درخت خطاى فازى بر يايه دو نوع توزيع امكان وقوع نقص در صنايع فر آيندى}

\section{عباس بك بكى'، نادر نبهانى '، باقر انورى يورّ‘"، غلامعباس شيرالى"} ' دانشجوى كارشناسى ارشد مهندسى شيمى (مهندسى ايمنى، بهداشت و محيط زيست)، گروه مهندسى ايمنى و حفاظت فنى، دانشكده نفت آبادان،

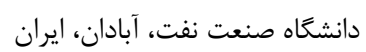

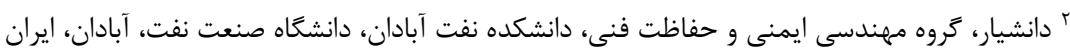

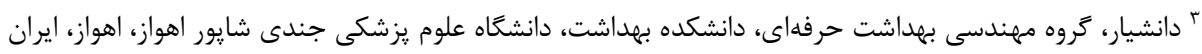
* نويسنده مسئول: باقر انورى يور، كروه مهندسى ايمنى و حفاظت فنى، دانشكده نفت آبادان، دانشعاه صنعت نفت، آبادان، ايران. ايميل:put.ac.ir

\section{جكيده}

سابقه و هدف: ارزيابى ريسك احتمالى با استفاده از آناليز درخت خطا (FTA: Fault Tree Analysis)

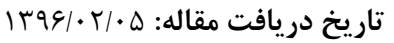

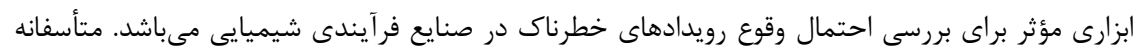

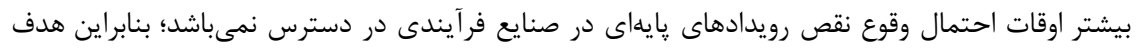

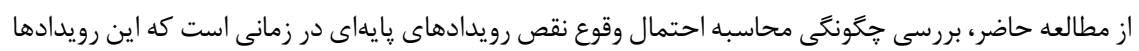
دادههاى نقص دقيق ندارند.

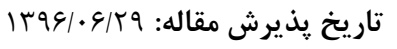
تمامى حقوق نشر براى دانشكاه علوم يزشكى همدان محفوظ است.

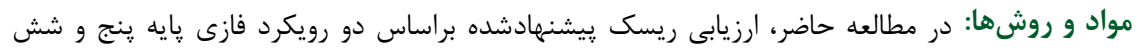

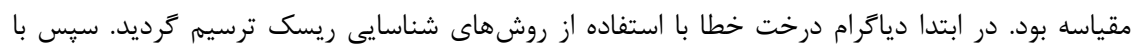

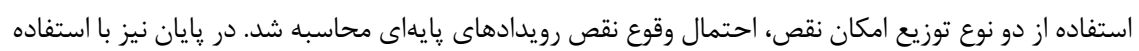

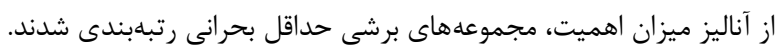

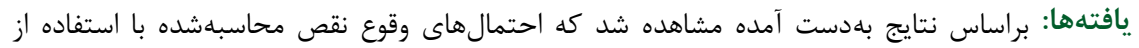

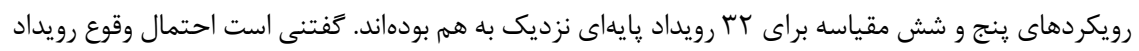

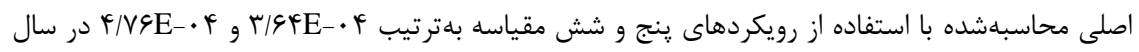

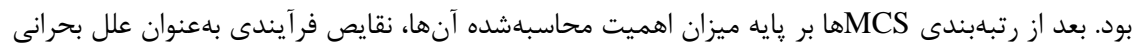
TE

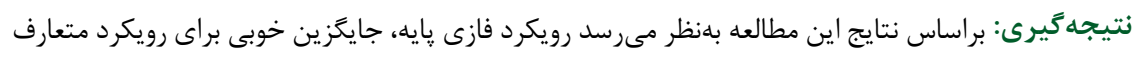

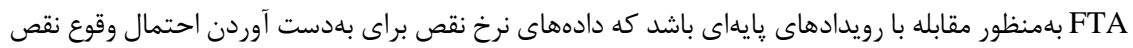

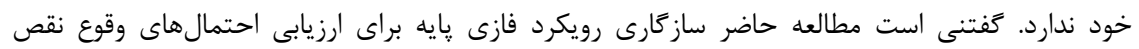
رويدادهاى קايهاى را تأييد كرده است.

وازَّان كليدى: آناليز درخت خطاى فازى؛ احتمال وقوع نقص؛ امكان نقص؛ قضاوت خبركان؛ منطق فازى

زيست و مراكز جمعيتى بهدنبال داشته باشد [ب]. بخش كلاوس مهرمترين بخش SRU از نظر بازدهى تصفيه

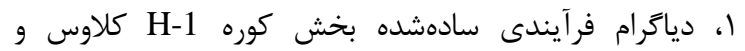

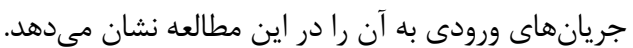
براساس مطالعه حاضر، ارزيابى ريسك احتمالى (

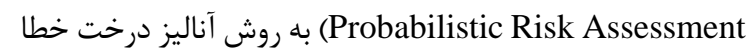
فرآيند سيستماتيك ارزيابى (FTA: Fault Tree Analysis)
واحدهاى مختلف در صنايع فر آيندى بهخصوص واحد بازيافت كو فرآيندها بلهمار مىروند. هدف SRU تصفيه و پالايش كازهاى

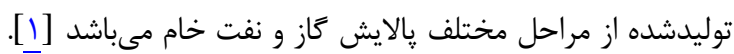

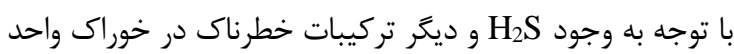

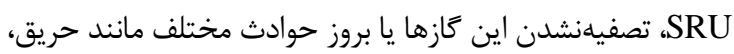

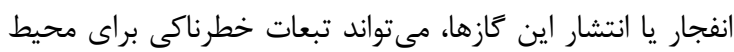




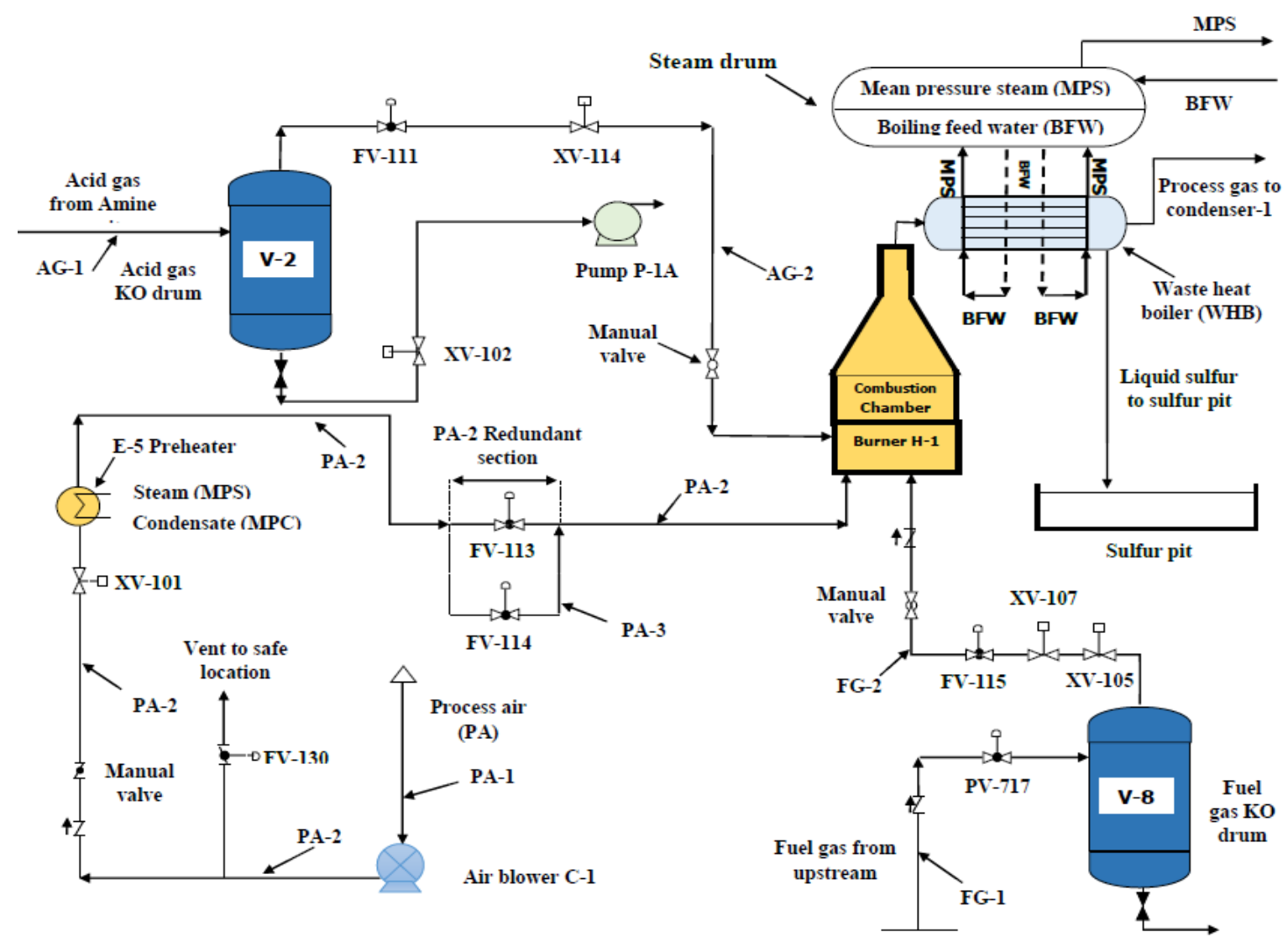

شكل ا: دياترام فر آيندى بخش كوره واكنش حرارتى كلاوس واحد SRU در مطالعه حاضر

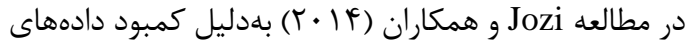

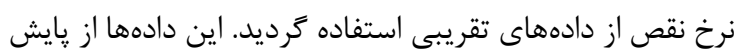

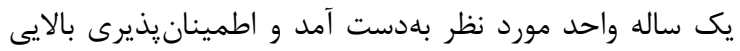

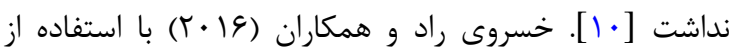

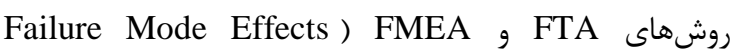
(Analysis

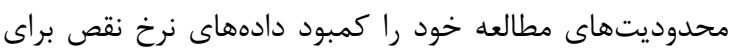

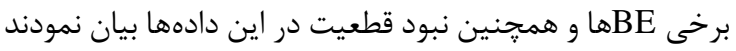

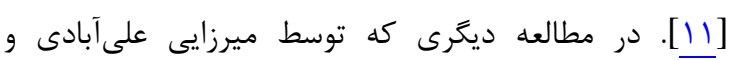

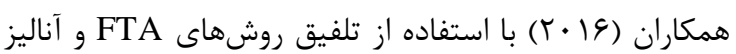

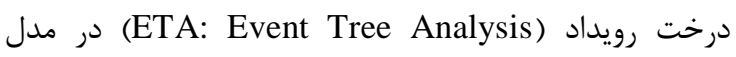
״إِيونى (Bowtie) انجام شد، براى رفع مشكل قطعىنبودن

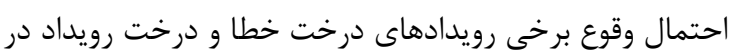

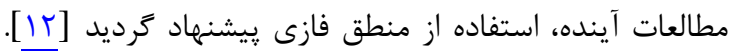

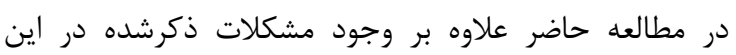
مطالعات، واحد SRU در مراحل اوليه عمليات فرآيندى قرار

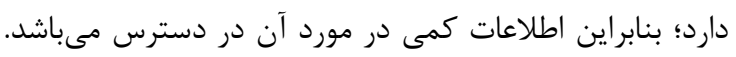

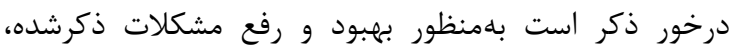

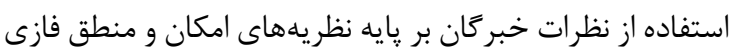

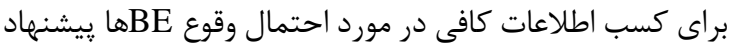

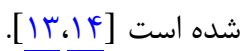
با توجه به محدوديتهاى ذكرشده براى رويكرد متعارف

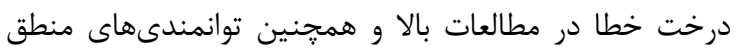

ريسك حوادث و رويدادهاى خطرناى از نظر احتمال وقوع

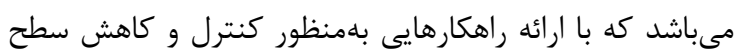

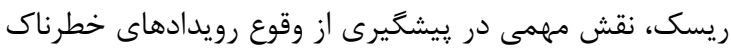

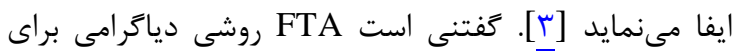

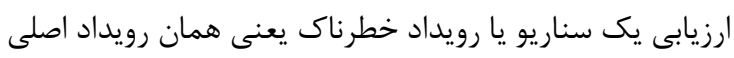
و علل وقوع آن بلصورت كمى و كيفى (TE: Top Event) مى باشد. اساسى ترين مرحله كمى FTA، محاسبه نرخ و احتمال

وقوع رويدادهاى پايهاى (BE: Basic Event) است [ه، مب]. در مطالعات متعارف FTA در صنايع فرآيندى براى تعيين

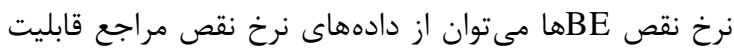

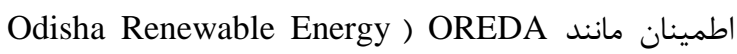
Center for Chemical ) CCPS (Development Agency

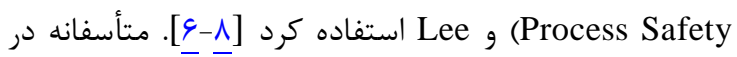
اين منابع نيز براى برخى از BEها، نرخ نقايص وجود ندارد يا

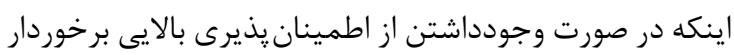

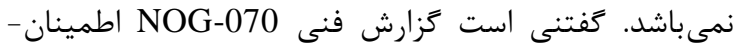
يذيرى دادههاى نرخ نقص يكى جزء را براى استفاده در

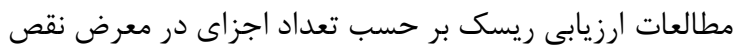

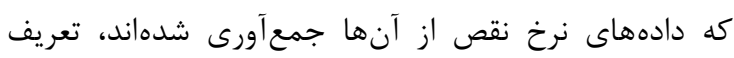

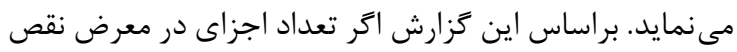

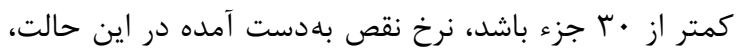

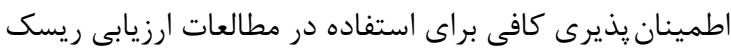
نخواهد داشت [q]. 
از طريق دروازههاى منطقى ايجاد مىشود. از معمولترين اين

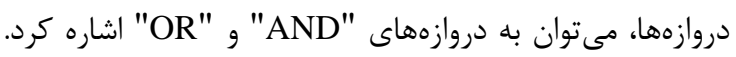

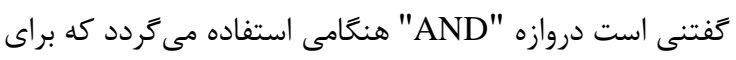

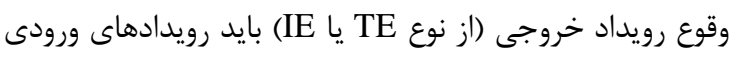

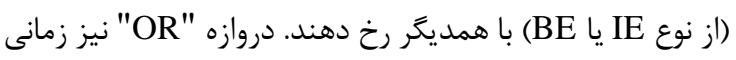

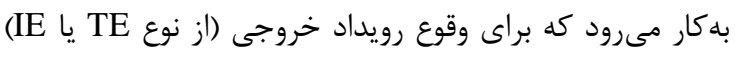

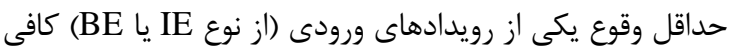

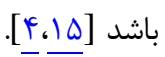
در اين مطالعه براساس مدل ارائهشده توسط Guo و

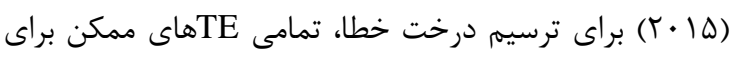

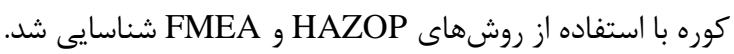
همجنين در اين مدل از ييامدهاى (Consequences) مطالعات

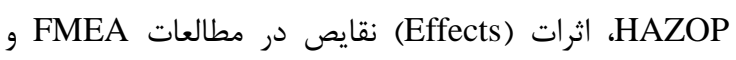
نظرات خبركان براى شناسايى TE ممكن استفاده شد. علل اين

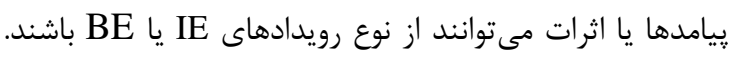

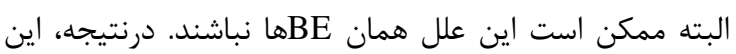

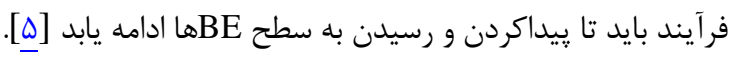

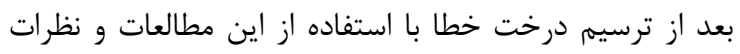

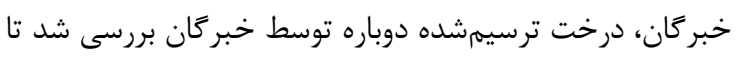
صحت آن ارزيابى كردد.
فازى، نظريه امكان و نظرات خبركان، با استفاده از تلفيق نظريه

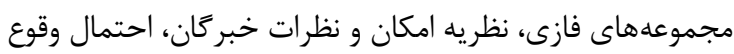

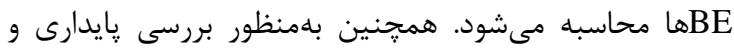

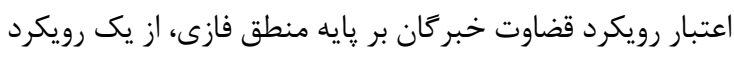

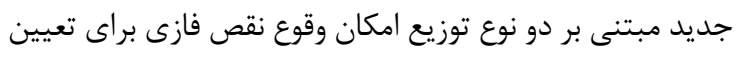
احتمال وقوع نقص رويدادها استفاده خواهد شد.

\section{مواد و روشها}

مطالعه مقطعى حاضر در واحد بازيافت گوگرد يك يالايشعاه

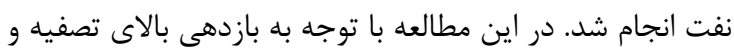

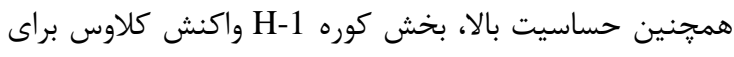

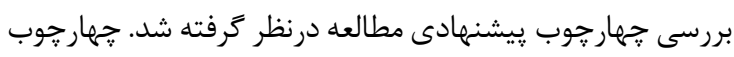

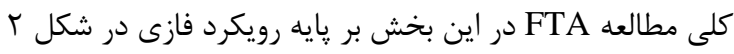
آمده است. مراحل مطالعه بلهورت زير مىباشد:

\section{ا. ترسيم ساختار درخت خطا بر پايه شناسايى}

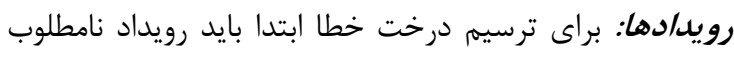

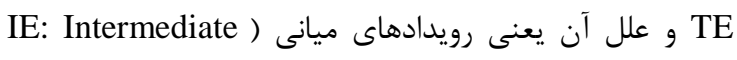

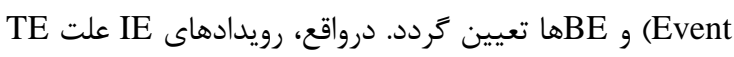
و رويدادهاى BE علت BE ها مي باشند. ارتباط ميان اين رويدادها

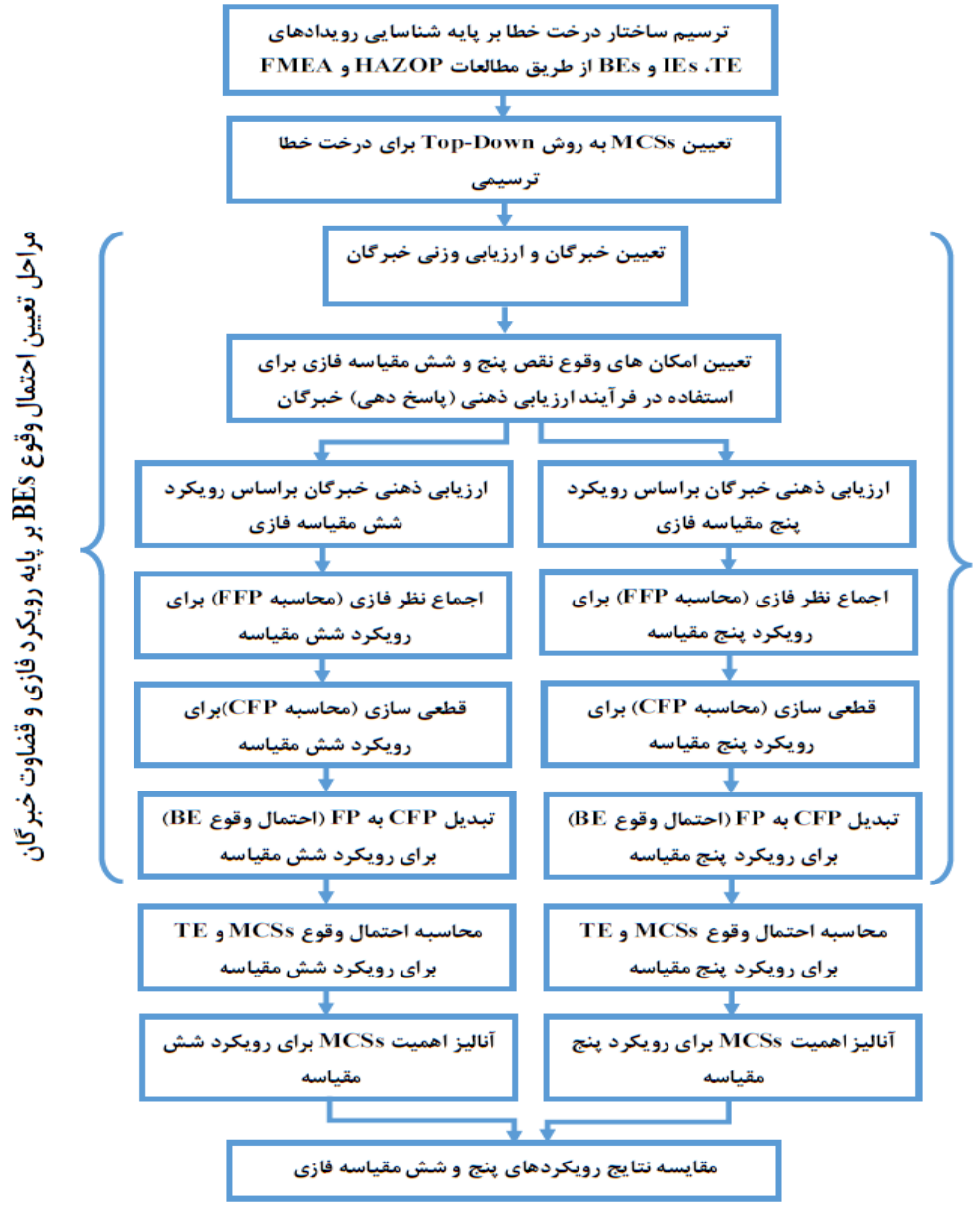

شكل r: جهارجوب كلى مطالعه در بخش كوره واكنش كلاوس SRU 
براساس معيارهاى جدول ا، فاكتور وزنى نسبى براى هريك از

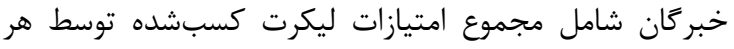
خبره تقسيم بر مجموع امتيازات كسبشانده توسط همه خباز خبر كان

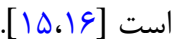

كام r: تعيين توزيع /مكانهاى وقوع نقص فازى (فازى سازى) و ارزيابى ذهنى خبركان: در اين مرحله براى

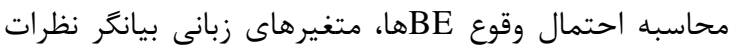
خبر كان در قالب توزيع امكان وقوع نقص ( FPD: Failure هPPD تعان Possibility Distribution بهعنوان پاسخ يرسشنامه امكان وقوع BEها توسط خبركان استفاده مى شود. كفتنى است توابع عضويت مثلثى بهان بهدليل

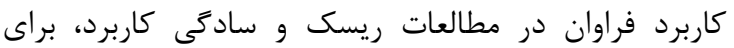

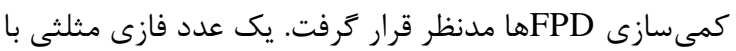

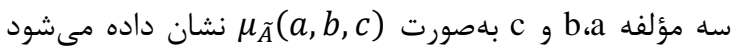

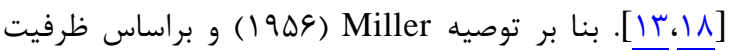

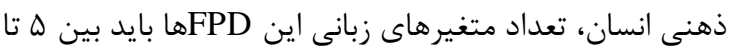

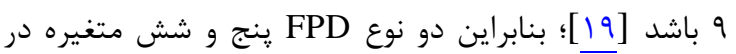
جدول r كه توسط توابع عضويت مثلنى فازى كمىسازى

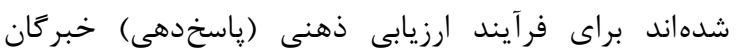

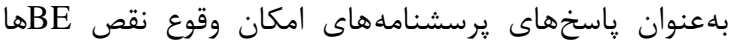

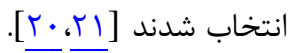

كام سّ: اجماع نظر بين امكانهاى وقوع نقص فازى

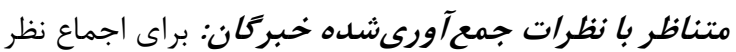

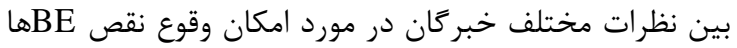
با توجه به در دسترس بودن وزن نسبى خبر دان دان، امكان وقوع امكان

جدول r: امكانهاى وقوع نقص و توابع عضويت فازى

\begin{tabular}{|c|c|}
\hline \multicolumn{2}{|c|}{ متغير هاى زبانى هنج مقياسه } \\
\hline تابع عضويت فازى & امكان وقوع نقص \\
\hline$\mu_{\mathrm{VL}}(\cdot / \cdot \cdot \cdot / \cdot \cdot \cdot / \mathrm{T} \Delta)$ & خيلى كم (VL) \\
\hline$\mu_{\mathrm{L}}(\cdot / \cdot \cdot \cdot \cdot / T \Delta \cdot \cdot / \Delta \cdot)$ & كم (L) \\
\hline$\mu \mathrm{M}(\cdot / T \Delta \cdot \cdot / \Delta \cdot ، \cdot / \mathrm{V} \Delta)$ & متوسط (M) \\
\hline$\mu_{\mathrm{H}}(\cdot / \Delta \cdot \cdot \cdot / \mathrm{V} \Delta, 1 / \cdot \cdot)$ & زياد (H) \\
\hline$\mu_{\mathrm{VH}}(\cdot / \mathrm{V} \Delta, 1 / \cdots, 1 / \cdots)$ & خيلى زياد (VH) \\
\hline \multicolumn{2}{|c|}{ متغير هاى زبانى شش مقياسه } \\
\hline تابع عضويت فازى & امكان وقوع نقص \\
\hline$\mu \operatorname{VL}(\cdot / \cdot \cdot \cdot / \cdot \cdot ، / / \cdot)$ & خيلى كم (VL) \\
\hline$\mu_{\mathrm{L}}(\cdot / \cdot \cdot \cdot \cdot / \tau \cdot \cdot \cdot / \uparrow \cdot)$ & كم (L) \\
\hline$\mu_{\mathrm{FL}}(\cdot / r \cdot ، \cdot / \kappa \cdot ، \cdot / \varepsilon \cdot)$ & نسبتاً كم (FL) \\
\hline$\mu \mathrm{FH}(\cdot / \boldsymbol{\kappa} \cdot ، \cdot|\xi \cdot ، \cdot| \Lambda \cdot)$ & نسبتاً زياد (FH) \\
\hline$\mu_{\mathrm{H}}(\cdot|\xi \cdot ، \cdot| \Lambda \cdot ، \mid / \cdot \bullet)$ & زياد (H) \\
\hline$\mu \mathrm{VH}(\cdot|\Lambda \cdot ،| / \cdot \cdot \mid / \cdot \cdot)$ & خيلى زياد (VH) \\
\hline
\end{tabular}

r. r. تعيين مجموعههاى برشى حداقل: يك مجموعه برشى (CS: Cut Set)

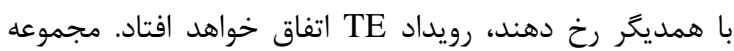

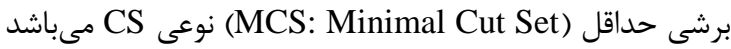
كه توسط قوانين جبر بولين قابليت سادهسازى بيشتر ندارد.

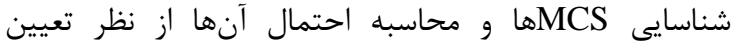
مسيرهاى مختلف وقوع TE و همجنين محاسبه احتمال وقوع آن آن آنال

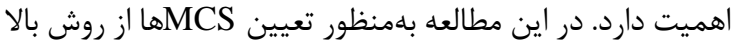

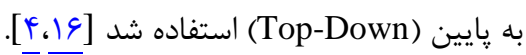

r. تعيين احتمال وقوع BBE بر بإيه رويكرد فازى:

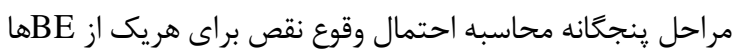
براساس دو رويكرد فازى يايه ينج و شش مقياسه در كَامهاى زير آورده شده است:

تام ا: تعيين خبركان و/رزيابى وزنى خبركان: براساس

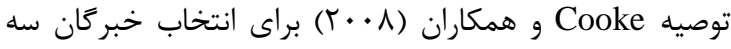

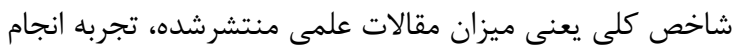

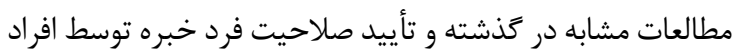

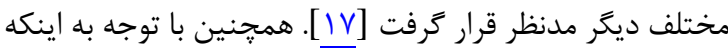
خبركان داراى معيارهاى مختلفى همجون: تجربه، تحصيلات،

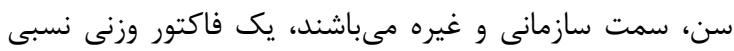

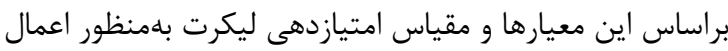

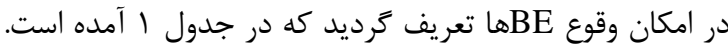

جدول ا: معيارهاى جهار كانه وزنى خبر كان

\begin{tabular}{|c|c|c|c|}
\hline امتياز & رتبهبندى معيار & معيار وزن خبركان & رديف \\
\hline$\Delta$ & مدير، مهندس ارشد & \multirow{5}{*}{ عنوان سازمانى } & \multirow{5}{*}{1} \\
\hline F & سريرست واحد & & \\
\hline r & مهندس & & \\
\hline r & تكنسين & & \\
\hline 1 & ايراتور & & \\
\hline$\Delta$ & بيش از • ب & \multirow{5}{*}{ ميزان تجربه كارى } & \multirow{5}{*}{ r } \\
\hline f & $r \cdot-r \cdot$ & & \\
\hline r & $1 \cdot-19$ & & \\
\hline r & $9-9$ & & \\
\hline 1 & كمتر از & & \\
\hline$\Delta$ & 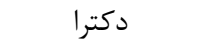 & \multirow{5}{*}{ ميزان تحصيلات } & \multirow{5}{*}{ r } \\
\hline r & كارشناسى ارشد & & \\
\hline r & كارشناسى & & \\
\hline r & كاردانى & & \\
\hline 1 & كمتر از دييلم & & \\
\hline f & بيش از •ه & \multirow{4}{*}{ سن (برحسب سال) } & \multirow{4}{*}{ f } \\
\hline r & $r \cdot-\omega \cdot$ & & \\
\hline r & r. & & \\
\hline 1 & كمتر از • r & & \\
\hline
\end{tabular}


ها در ساختار درخت خطا مىتوان از رابطه 9 استفاده نمود [FE].

$I M\left(M C S_{j}\right)=\frac{P\left(M C S_{j}\right)}{P(T E)}$

در رابطه بالا، IM (MCSj) بيانكر ميزان اهميت مجموعه

$$
\text { برشى حداقل j مى باشد. }
$$

يافتهها

با انجام مطالعات HAZOP و HMEA و همجنين مصاحبه با

خبركان فرآيندى واحد SRU، ريسكهاى بخش كوره H-1

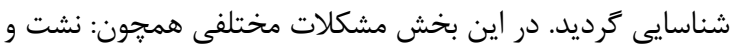

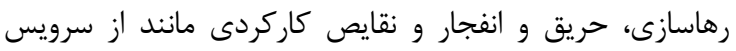
خارجشدن (Shutdown) بيشترين فراوانى وقوع را در بين پيامدها

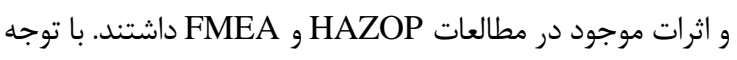

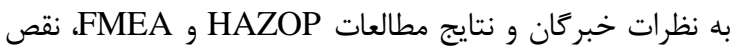
Shutdown

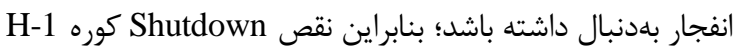

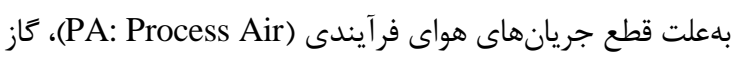

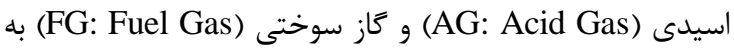

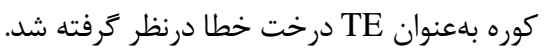

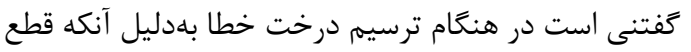

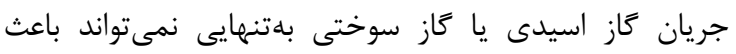
كوره شود، اين دو رويداد براى Shutdown

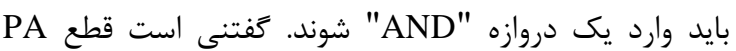

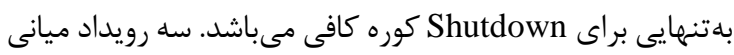

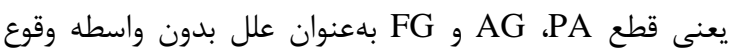
Shutdown

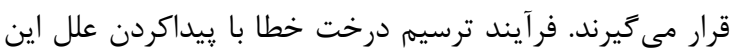

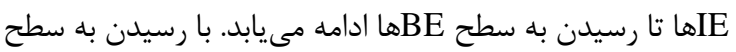

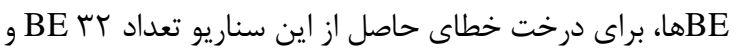

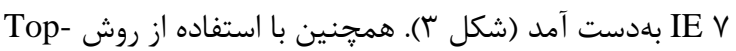

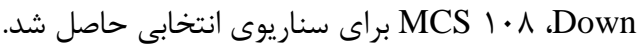

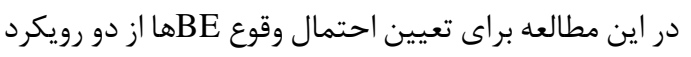

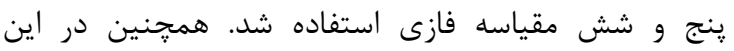

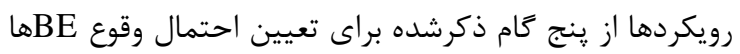

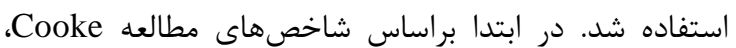

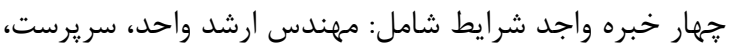

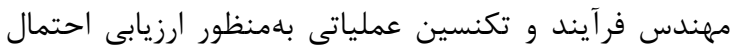

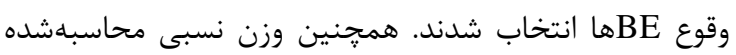

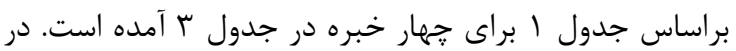

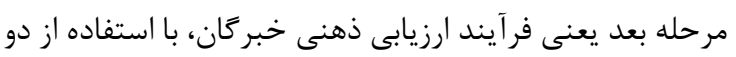

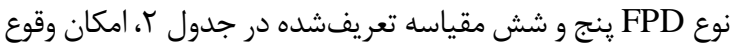

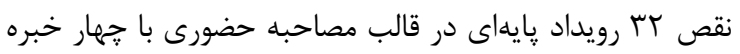
مورد نظر مشخص كرديد. درخور ذكر است در اين مطالعه براى باى
AFFP: Aggregated Fuzzy Failure ( نص فازى اجماعيافته

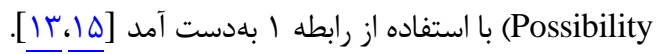

$$
A F F P=\mu_{A g g}(x)=\sum_{j=1}^{n} w_{j} \mu_{i j}
$$

رابطه |

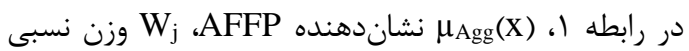

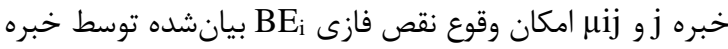
j مىباشد. همجنين n تعداد كل خبر كان مى فياشد.

\section{كام F: قطعىسازى/مكان وقوع نقص فازى اجماع يافته:}

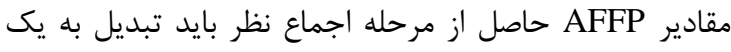

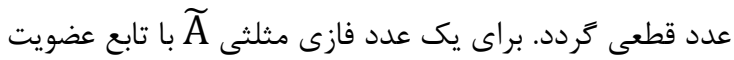
فازى (a,b,c)

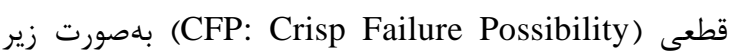

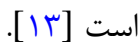

$$
\text { رابطه }
$$

كام ه: تبديل CFP به احتمال وقوع نقص BE أما: مقادير بهدست آمده براى هر BE در مرحله قطعىسازى،

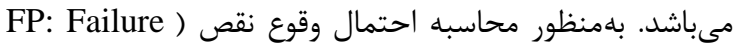
ها از مقادير CFP (Probability

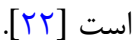

$F P=\left\{\begin{array}{cl}\frac{1}{10^{K}} & C F P \neq 0 \\ 0 & C F P=0\end{array} ; K=\left[\frac{1-C F P}{C F P}\right]^{\frac{1}{3}} \times 2.301 \quad\right.$ رابط

در رابطه بالا، K يك متغير حد واسط است كه فقط تابع

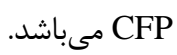

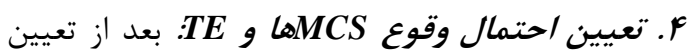

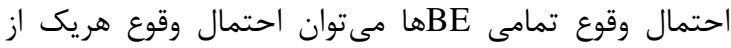

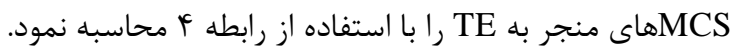
احتمال وقوع TE نيز از رابطه ه محاسبه مى كردد [19].

$$
P\left(M C S_{j}\right)=\prod_{i=1}^{n} F P\left(B E_{i}\right) \quad \text { رابطه }
$$$$
P(T E)=1-\prod_{j=1}^{k}\left(1-P\left(M C S_{j}\right)\right) \quad \text { رابطه }
$$

در رابطه Fا، (FP (BE

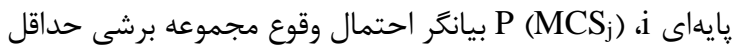

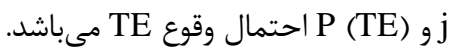

ه. تعيين ميزان اهميت MCSها: بهمنظور تعيين ميزان

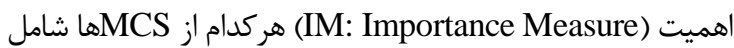



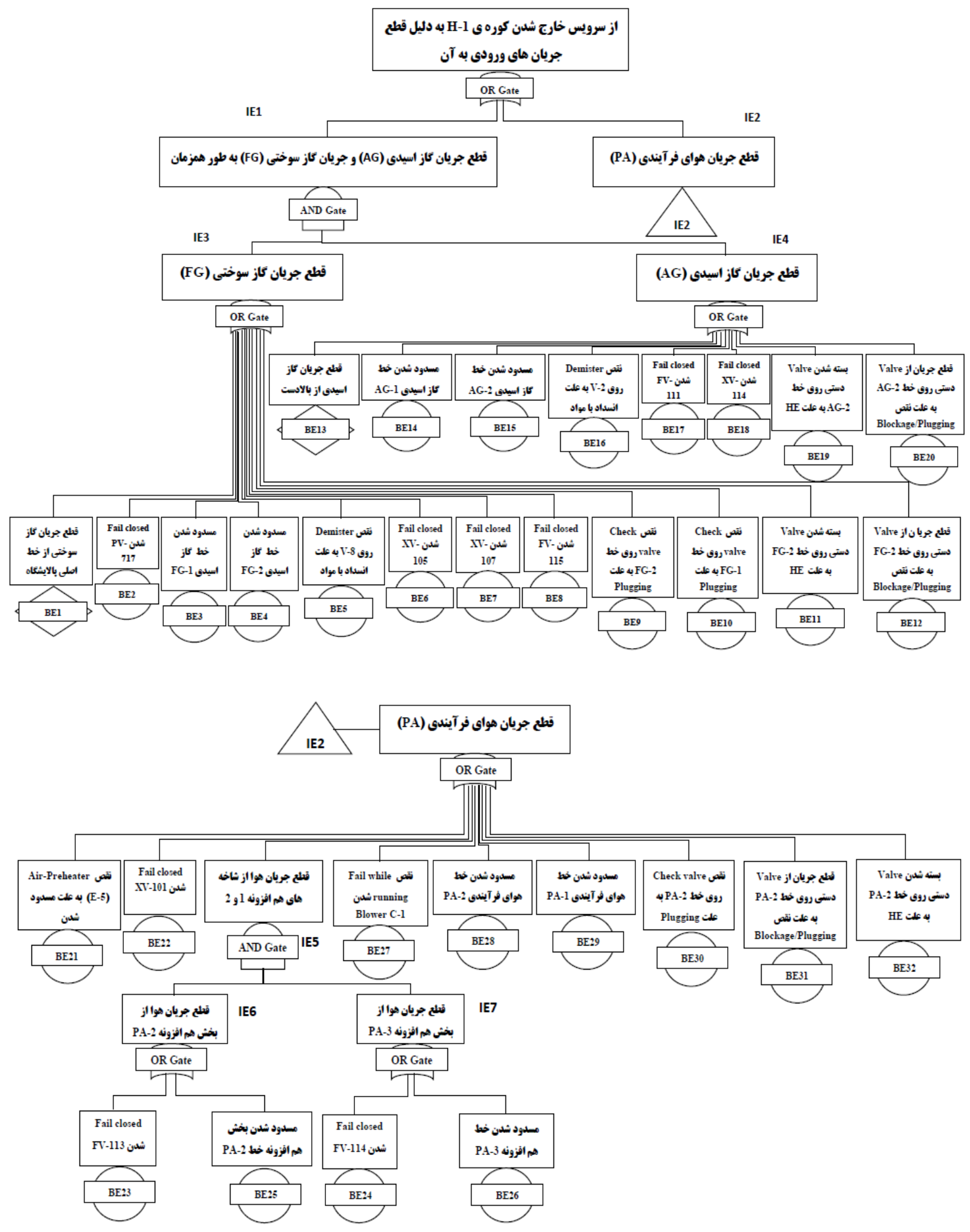

شكل rّ: ساختار درخت خطا براى سناريوى از سرويس خارجشدن كوره ا واكنش كلاوس

جدول זّ: فاكتور وزنى نسبى محاسبهشده براى خبركان براساس معيار هاى جهار كانه

\begin{tabular}{|c|c|c|c|c|c|c|}
\hline فاكتور وزنى & امتياز وزنى & سن & تجربه & تحصيلات & عنوان & خبر كان \\
\hline.$/ 49199 \mathrm{~V}$ & if & $r$ & q & $r$ & q & خبره 1 \\
\hline$\cdot / r q 199 V$ & if & r & r & f & $\Delta$ & خبره r \\
\hline rזrی• & 1. & r & r & r & $r$ & خبره ץ \\
\hline rrאט• & 1. & r & 1 & r & r & خبره F \\
\hline 1 & $\psi_{\lambda}$ & & & & & \\
\hline
\end{tabular}


ها تبديل شدند و نتايج آن براى رويكرد ينج مقياسه فازى در

ستون زينجم جدول \& أمده است.

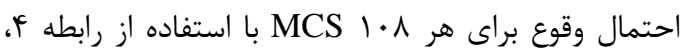

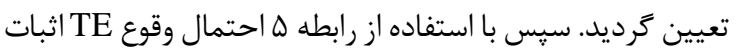

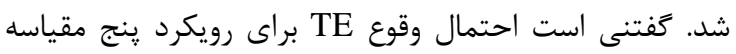

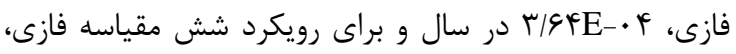

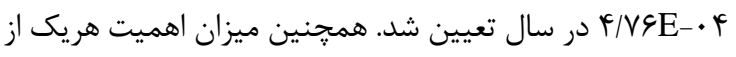

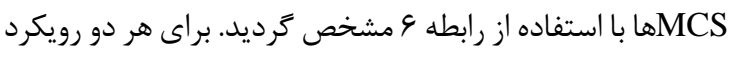
ينج و شش مقياسه، نتايج حاصل از اين مرحله فقط براى

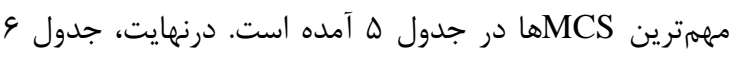

دورى از افزايش حجم فقط نتايج مراحل مختلف محاسبه احتمال

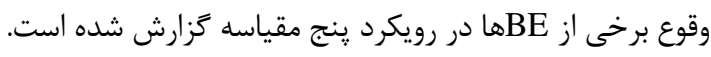

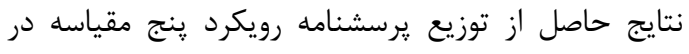

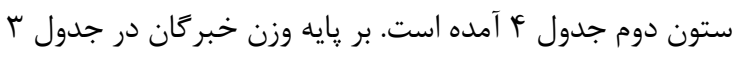

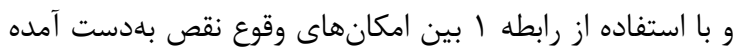

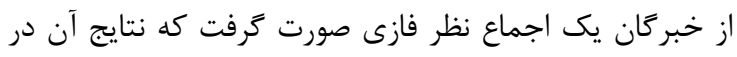

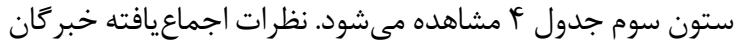

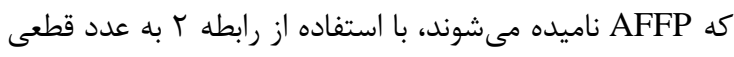

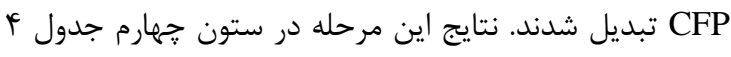

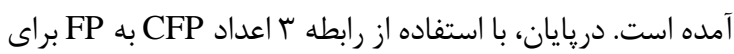

جدول fا: فرآيند ارزيابى ذهنى خبر كان، اجماع نظر و احتمال وقوع برخى از BEها براى رويكرد ينج مقياسه فازى

\begin{tabular}{|c|c|c|c|c|c|c|c|}
\hline \multirow{2}{*}{ تبديل CFP به FP } & \multirow{2}{*}{ مقادير CFP } & \multirow{2}{*}{ مقادير FFP } & \multicolumn{4}{|c|}{ فر آيند ارز يابى ذهنى خبركًان } & \multirow{2}{*}{$\mathbf{B E}$} \\
\hline & & & خبره F & خبره r & خبره r & خبره ا & \\
\hline$r / 9 \wedge E_{-} \cdot \wedge$ &.$/ \cdot r \Lambda$ & $(\cdot, \cdot / / T \Delta, \cdot / T V \Delta)$ & $\mathrm{VL}$ & $\mathrm{L}$ & $\mathrm{L}$ & VL & 1 \\
\hline$r / q \vee E-\cdot \Delta$ &.$/ 1 r \Delta$ & $(\cdot / r \Delta \cdot \cdot \cdot / \Delta \cdot \cdot \cdot \cdot / V \Delta \cdot)$ & $\mathrm{L}$ & $\mathrm{H}$ & M & M & t \\
\hline$r / \wedge \Leftrightarrow E_{-} \cdot V$ &.$/ \cdot t t$ & $(\cdot ، \cdot / r \Delta \cdot ، \cdot / \Delta \cdot \cdot)$ & $\mathrm{L}$ & $\mathrm{L}$ & $\mathrm{L}$ & $\mathrm{L}$ & r \\
\hline$V / 94 E_{-} \cdot 9$ & r & $(\cdot / T \Gamma \Delta \cdot \cdot / T V \Delta, \cdot / g r \Delta)$ & $\mathrm{L}$ & M & M & $\mathrm{L}$ & f \\
\hline$r / q \vee E-\cdot \Delta$ &.$/ 1 r \Delta$ & $(\cdot / r \Delta \cdot \cdot \cdot / \Delta \cdot \cdot \cdot \cdot / V \Delta \cdot)$ & $\mathrm{L}$ & $\mathrm{H}$ & M & M & 4 \\
\hline$r / \wedge \Leftrightarrow E_{-} \cdot V$ & $\cdot / \cdot \operatorname{ct}$ & $(\cdot \cdot \cdot / T \omega \cdot \cdot \cdot / \Delta \cdot \cdot)$ & $\mathrm{L}$ & $\mathrm{L}$ & $\mathrm{L}$ & $\mathrm{L}$ & 9 \\
\hline$r / \wedge \wedge \mathrm{E}-\cdot \varphi$ & .1 .91 & $(\cdot / 1 \cdot F \cdot \cdot / T \wedge|\cdot \cdot| \Delta T I)$ & M & M & $\mathrm{L}$ & VL & 11 \\
\hline $1 / \Delta V E-\cdot r$ & $\cdot / 111$ & $(\cdot / F T V \cdot \cdot|G V V \cdot \cdot| A V \Delta)$ & M & $\mathrm{VH}$ & $\mathrm{H}$ & M & ir \\
\hline$৭ / \wedge \wedge E_{-} \cdot \vee \vee$ & $\cdot / \cdot \Delta r$ & $(\cdot / \cdot \Delta r, \cdot / r \Delta \cdot, \cdot / \Delta \cdot \cdot)$ & VL & M & $\mathrm{L}$ & $\mathrm{L}$ & If \\
\hline$r / q \vee E_{-} \cdot \Delta$ &.$/ 1 T \Delta$ & $(\cdot / r \Delta \cdot ، \cdot / \Delta \cdot \cdot \cdot / V \Delta \cdot)$ & M & M & M & M & 19 \\
\hline r/qVE-• $\Delta$ &.$/ 1 T \Delta$ & $(\cdot / r \Delta \cdot \cdot \cdot / \Delta \cdot \cdot \cdot / V \Delta \cdot)$ & $\mathrm{L}$ & $\mathrm{H}$ & M & M & iv \\
\hline$\wedge / \wedge \Lambda E_{-} \cdot \wedge$ & $\cdot / \cdot r k$ & $(\cdot . \cdot / I V V . \cdot / \& T V)$ & $\mathrm{L}$ & $\mathrm{L}$ & $\mathrm{L}$ & VL & 19 \\
\hline$I / r \wedge E_{-} \cdot V$ & $\cdot 1 \cdot r 4$ & $(\cdot . \cdot / 19 \Lambda ، \cdot / 44 \Lambda)$ & VL & $\mathrm{L}$ & $\mathrm{L}$ & $\mathrm{L}$ & r. \\
\hline$F / r \mu E_{-} \cdot V$ & $.1 \cdot 4 \Delta$ & $(\cdot / \cdot \Delta T \cdot \cdot / / V V ، \cdot / G T V)$ & VL & M & $\mathrm{L}$ & VL & r) \\
\hline$r / q \vee E-\cdot \Delta$ &.$/ 1 T \Delta$ & $(\cdot / T \Delta \cdot ، / / \Delta \cdot \cdot \cdot / V \Delta \cdot)$ & $\mathrm{L}$ & $\mathrm{H}$ & M & M & rt \\
\hline$V / \cdot 9 E_{-} \cdot 9$ & . $/$ tr & $(\cdot \cdot \cdot / \cdot V \Psi, \cdot \cdot / T r)$ & VL & VL & $\mathrm{L}$ & VL & ra \\
\hline$r / V T E-\cdot \varphi$ & .1 .99 & $(\cdot / \cdot V T ، / K T r$ • • •/DVT) & $\mathrm{L}$ & $\mathrm{L}$ & M & $\mathrm{L}$ & re \\
\hline$r / T Y E_{-} \cdot r$ & 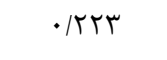 & $(\cdot|\Delta \Delta r ، \cdot| \Lambda \cdot r ، \mid)$ & $\mathrm{H}$ & $\mathrm{VH}$ & $\mathrm{H}$ & $\mathrm{H}$ & TV \\
\hline r/qVE-1. & $.1 \cdot 1 \mathrm{f}$ & $(\cdot \cdot \cdot \cdot / r \Delta \cdot)$ & VL & VL & VL & VL & r \\
\hline$V / \cdot 9 E_{-} \cdot 9$ &.$/ \cdot T t$ & 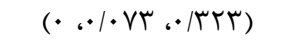 & VL & VL & $\mathrm{L}$ & VL & rt \\
\hline
\end{tabular}

جدول ه: آناليز اهميت MCSها براى دو رويكرد پينج و شش مقياسه فازى

\begin{tabular}{|c|c|c|c|c|}
\hline \multirow[b]{2}{*}{ 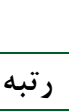 } & \multirow[b]{2}{*}{ ميزان اهميت } & \multirow[b]{2}{*}{ احتمال وقوع } & \multicolumn{2}{|c|}{ رويكرد متغيرهاى زبانى ينج مقياسه فازى هايه } \\
\hline & & & رويدادهاى موجود در MCS & MCS Mماره \\
\hline 1 & $N / q \cdot E-\cdot 1$ & T/TFE- $\cdot F$ & BE27 & MCS103 \\
\hline r & $1 / \cdot 9 E-\cdot 1$ & $r / q \vee E-\cdot \Delta$ & BE22 & $\operatorname{MCS} 98$ \\
\hline r & 1/19E-•r & $F / r r E-\cdot V$ & BE21 & $\operatorname{MCS} 97$ \\
\hline r & $1 / 94 E-\cdot \Delta$ & $V / \cdot 9 \mathrm{E}-.9$ & BE28 & MCS104 \\
\hline r & $1 / 94 \mathrm{E}-\cdot \Delta$ & $\mathrm{V} / \cdot 9 \mathrm{E}-\cdot 9$ & BE29 & MCS105 \\
\hline r & $1 / 94 E-\cdot \Delta$ & $V / \cdot 9 \mathrm{E}-\cdot 9$ & BE30 & $\operatorname{MCS} 106$ \\
\hline r & $1 / q 4 E-\cdot \Delta$ & $V / \cdot 9 \mathrm{E}-\cdot 9$ & BE32 & MCS108 \\
\hline$\Delta$ & $|/ V| E-\cdot \Delta$ & 9/rTE-. 9 & $\mathrm{BE} 13, \mathrm{BE} 2$ & MCS9 \\
\hline$\Delta$ & $|/ V| E_{-} \cdot \Delta$ & $9 / r T E-\cdot q$ & BE13, BE6 & MCS41 \\
\hline
\end{tabular}




\begin{tabular}{|c|c|c|c|c|}
\hline \multirow[b]{3}{*}{ رتبه } & \multirow[b]{3}{*}{ ميزان اهميت } & \multirow[b]{3}{*}{ احتمال وقوع } & \multicolumn{2}{|r|}{ ادامه جدول هـ. } \\
\hline & & & \multicolumn{2}{|c|}{ رويكرد متغيرهاى زبانى شش مقياسه فازى پايه } \\
\hline & & & MCS رويدادهاى موجود در & MCS Mماره \\
\hline 1 & $9 / 4 r E-\cdot 1$ & $\boldsymbol{F} / \boldsymbol{F} \wedge \mathrm{E}_{-} \cdot \boldsymbol{r}$ & BE27 & MCS103 \\
\hline r & $\Delta / \Lambda \cdot E-\cdot r$ & $T / V \Leftrightarrow E-\cdot \Delta$ & BE22 & MCS98 \\
\hline r & $r / \Lambda \cdot E-\cdot r$ & $1 / r r E-\cdot V$ & BE21 & MCS97 \\
\hline r & $1 / \Delta V E-\cdot \Delta$ & $V / F V E-\cdot q$ & $\mathrm{BE} 13, \mathrm{BE} 2$ & MCS9 \\
\hline r & $1 / \Delta V E-\cdot \Delta$ & $V / F V E-\cdot q$ & BE13, BE6 & MCS41 \\
\hline i & $1 / \Delta \vee E-\cdot \Delta$ & $V / F V E-\cdot q$ & BE13, BE7 & MCS49 \\
\hline r & $1 / \Delta V E-\cdot \Delta$ & $V / F V E-\cdot q$ & $\mathrm{BE} 13, \mathrm{BE} 8$ & MCS57 \\
\hline$\Delta$ & $T / r \wedge E-\cdot \varphi$ & $r / r \wedge E-\cdot q$ & $\mathrm{BE} 13, \mathrm{BE} 4$ & MCS25 \\
\hline
\end{tabular}

نتايج بهدست آمده درباره احتمال وقوع تمامى BEها براساس

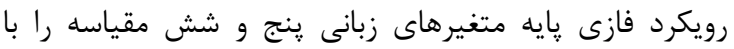

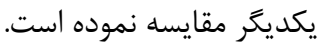

هدف اصلى از انجام اين مطالعه، رفع مشكل كمبود

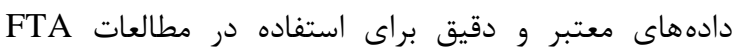

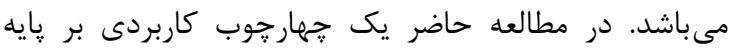
رويكرد جديد منطق فازى بهمنظور حل اين مشكلات ارائه دائه

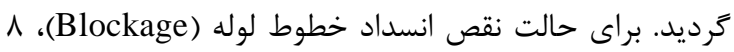

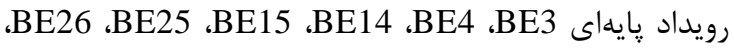

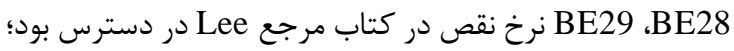

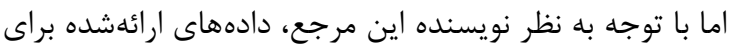

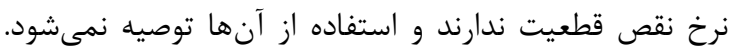

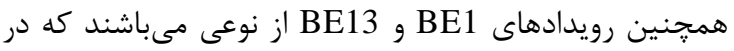
كتاب هاى قابليت اطمينان نرخ نقصى براى آنها وجود ندائ ندارد.

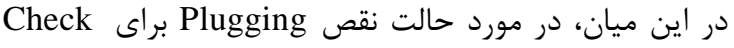

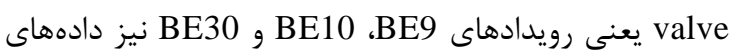
نرخ بهصورت تفكيكشده حتى در مرجع معتبر OREDA رائه

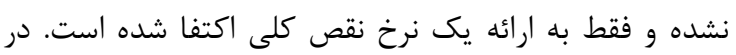

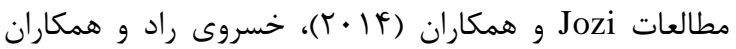

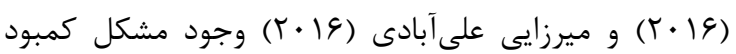
داده هاى نرخ نقص و نبود قطعيت در صنايع فرآيندى كزارش كرديد؛ بنابراين وجود اين مشكلات استفاده از رويكرد نوين نوردين

$$
\text { منطق فازى را توجيه مىنمايد [ب إ-1-1]. }
$$

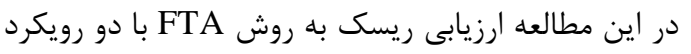

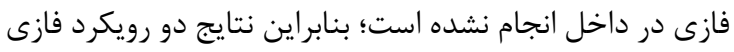

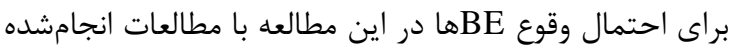

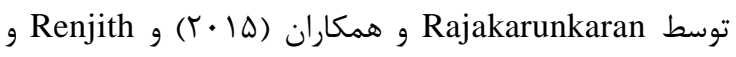

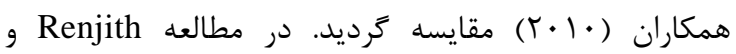

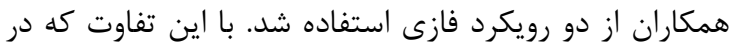

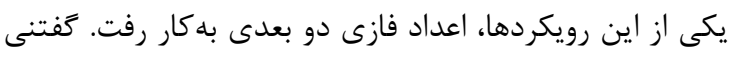

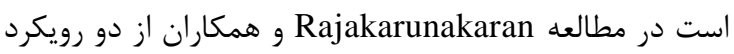

جدول \&: نتايج حاصل از رويكردهاى ينج و شش مقياسه

\begin{tabular}{|c|c|c|}
\hline \multicolumn{2}{|c|}{ احتمال وقوع (FP) } & \multirow{2}{*}{$\begin{array}{r}\text { BE } \\
\text { Bماره }\end{array}$} \\
\hline رويكرد شش مقياسه & رويكرد ينج مقياسه & \\
\hline$V / \Delta F E_{-} \cdot q$ & $r / 9 \wedge E_{-} \cdot \wedge$ & 1 \\
\hline$r / V \& E_{-} \cdot \Delta$ & $r / 9 \vee E_{-} \cdot \Delta$ & r \\
\hline$\Lambda / \Delta F E_{-} \cdot \Lambda$ & $r / \wedge ৎ E_{-} \cdot V$ & r \\
\hline$\Lambda / V \wedge E-. \varphi$ & $V / G \mid F E-. q$ & r \\
\hline$r / \wedge \Delta E_{-} \cdot \varphi$ & $V / \varphi+E-\cdot \varphi$ & $\Delta$ \\
\hline$r / V \varphi E_{-} \cdot \Delta$ & $r / 9 \vee E-\cdot \Delta$ & 4 \\
\hline$r / V \& E_{-} \cdot \Delta$ & $r / 9 \vee E_{-} \cdot \Delta$ & V \\
\hline$r / V \& E_{-} \cdot \Delta$ & $r / q \vee E-\cdot \Delta$ & $\wedge$ \\
\hline$\Lambda / \Delta f E_{-} \cdot \Lambda$ & T/AৎE-•V & 9 \\
\hline$\Lambda / \Delta F E_{-} \cdot \Lambda$ & $r / \wedge \& E_{-} \cdot V$ & $1 \cdot$ \\
\hline $1 / 1 T E_{-} \cdot \varphi$ & $\Gamma / 1 \wedge E_{-} \cdot \varphi$ & 11 \\
\hline$\Lambda / \Delta F E_{-} \cdot \Lambda$ & $r / \Lambda \varsigma E_{-} \cdot V$ & IT \\
\hline$r / V \backslash E_{-} \cdot r$ & $1 / \Delta V E_{-} \cdot f$ & Ir \\
\hline$r / r \mid E_{-} \cdot V$ & $q / \wedge \wedge E_{-} \cdot \vee$ & if \\
\hline$r / r \mid E_{-} \cdot V$ & $q / \wedge \wedge E_{-} \cdot \vee$ & 10 \\
\hline$\Delta / q r E_{-} \cdot \Delta$ & $r / 9 \vee E_{-} \cdot \Delta$ & 19 \\
\hline$\Lambda / \uparrow \notin \mathrm{E}_{-} \cdot \Delta$ & $r / q \vee E-\cdot \Delta$ & IV \\
\hline$\Lambda / \varphi \Leftrightarrow \mathrm{E}_{-} \cdot \Delta$ & $r / 9 \vee E_{-} \cdot \Delta$ & 11 \\
\hline$r / \mathcal{F} \mathrm{E}_{-} \cdot \Lambda$ & $\wedge / \wedge \wedge E_{-} \cdot \wedge$ & 19 \\
\hline 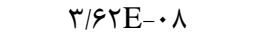 & $1 / r \wedge E_{-} \cdot \vee$ & $r \cdot$ \\
\hline $1 / \mu r E_{-} \cdot V$ & $r / r \mu E_{-} \cdot v$ & rI \\
\hline$r / V \varphi E_{-} \cdot \Delta$ & $r / q \vee E-\cdot \Delta$ & rt \\
\hline$r / V \varphi E_{-} \cdot \Delta$ & $r / 9 \vee E-\cdot \Delta$ & r \\
\hline$r / V \& E-\cdot \Delta$ & $r / q \vee E-\cdot \Delta$ & rF \\
\hline $1 / 91 E_{-} \cdot 9$ & $V / \cdot 9 E_{-} \cdot 9$ & $r \Delta$ \\
\hline$q / \uparrow \& \mathrm{E}_{-} \cdot \vee V$ & T/VTE-. & re \\
\hline$\varphi / f \wedge E_{-} \cdot \varphi$ & $r / r F E_{-} \cdot r$ & TV \\
\hline $1 / 91 E_{-} \cdot 9$ & $V / \cdot 9 E_{-} \cdot 9$ & $r \wedge$ \\
\hline $1 / 91 \mathrm{E}_{-} \cdot 9$ & $V / .9 E-.9$ & $r q$ \\
\hline $1 / 91 \mathrm{E}_{-} \cdot 9$ & $\mathrm{~V} / \cdot 9 \mathrm{E}-\cdot 9$ & $r$. \\
\hline$\Delta / r \Delta E-11$ & $r / 9 \vee E-1 \cdot$ & r \\
\hline $1 / 91 E_{-} \cdot 9$ & $V / .9 E_{-} \cdot 9$ & r \\
\hline
\end{tabular}


فر آيندى و به ميزان كمتر نقايص مكانيكى را دارد [بr.ه]]. در

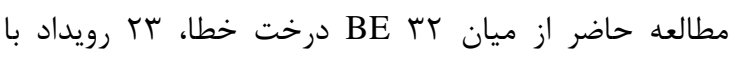
استفاده از روش HAZOP فرآيندى، 9 رويداد با استفاده از روش FMEA و ץ رويداد ديخر كه از نوع خطاى انسانى بودند

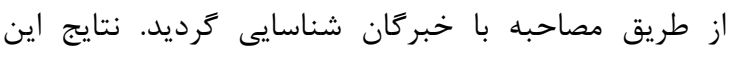

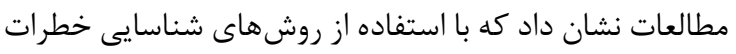

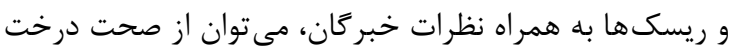

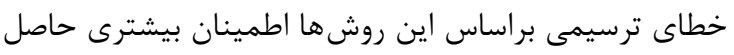

در اين مطالعه با كمركردن احتمال وقوع TE از عدد يك،

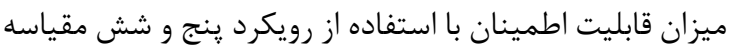

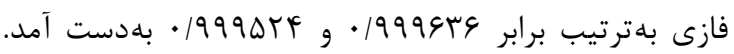

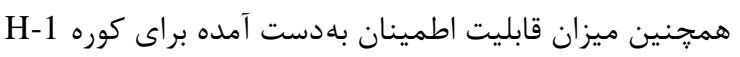

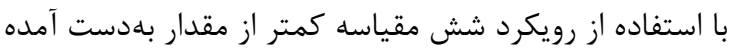
براى رويكرد ينج مقياسه بود.

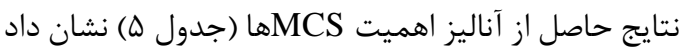

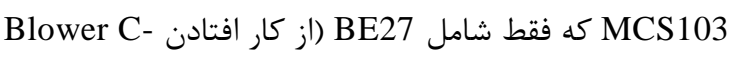

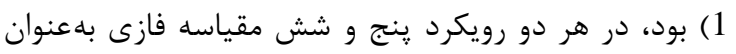

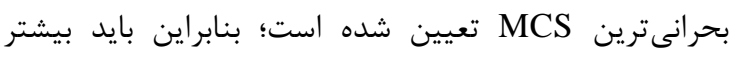

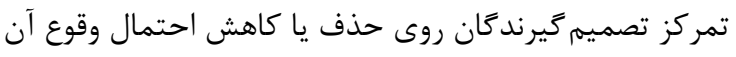

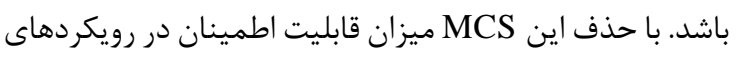

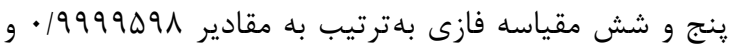

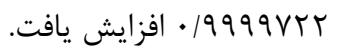

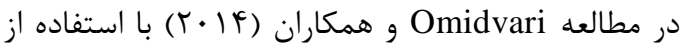

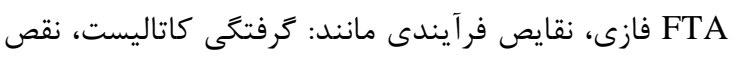

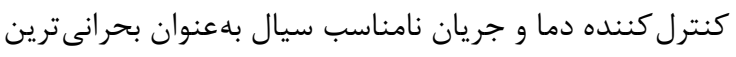

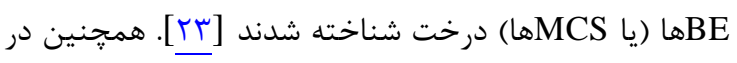

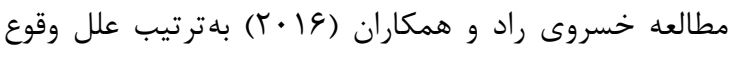

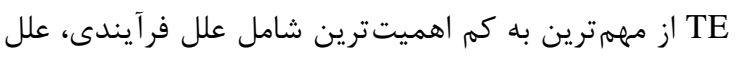

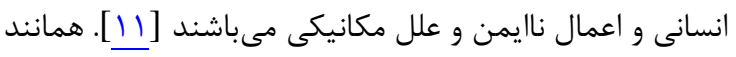

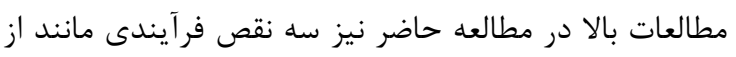

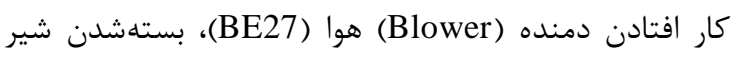

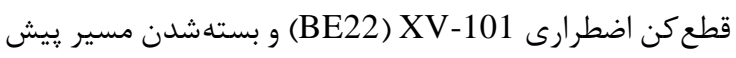
كرمكن (BE21) بهعنوان بحرانى ترين علل وقوع TE (BE22) شناخته

\section{نتيجه كيرى}

در اين مطالعه با توجه به اينكه نرخ نقص كافى براى برخى

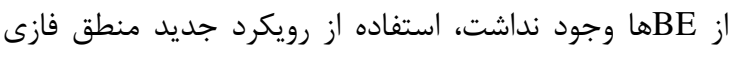

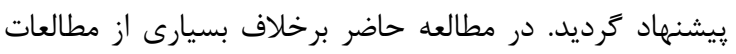

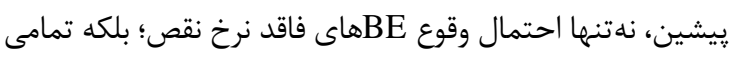

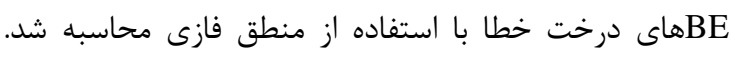

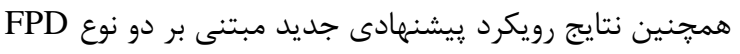

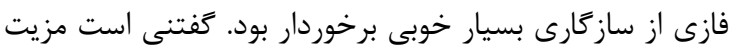

فازى با دو كروه ناهمكون مختلف از خبركان استفاده شد

در اين مطالعه دليل اصلى استفاده از دو رويكرد فازى،

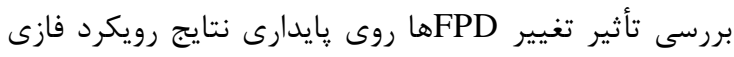

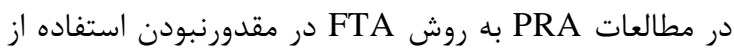

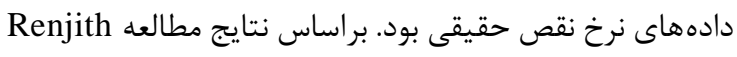

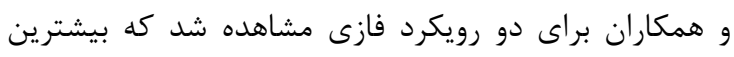

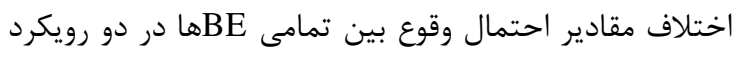

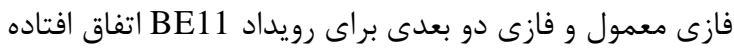

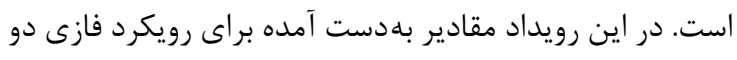

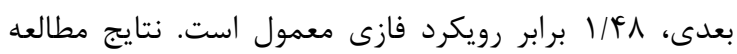
Rajakarunakaran

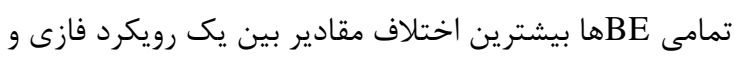

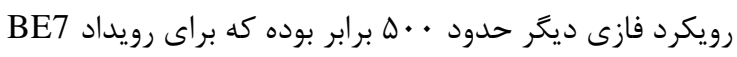

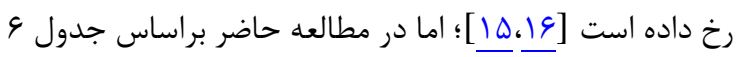

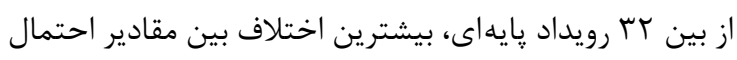

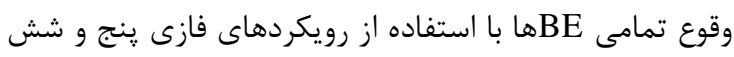

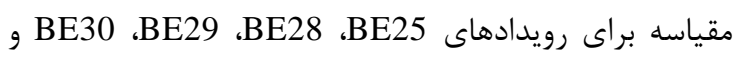

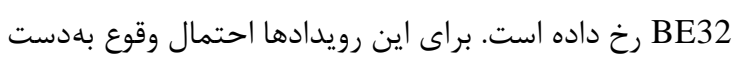

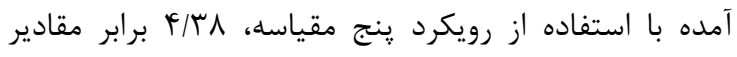

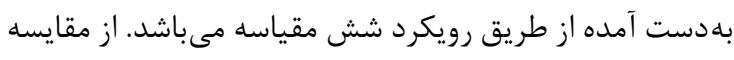

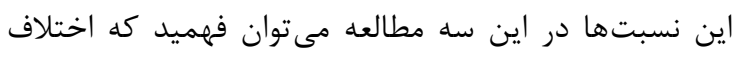

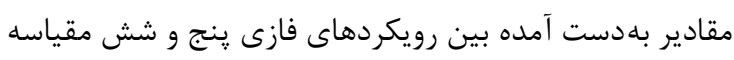
اين مطالعه در بدترين و بيشترين مقدار خود (يعنى براى

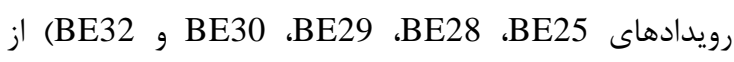

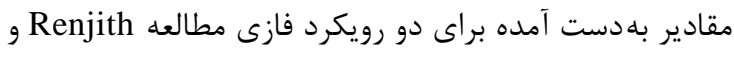

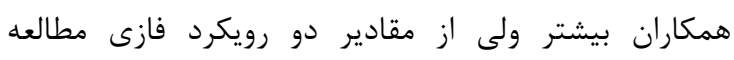

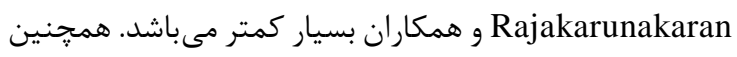
اين تفسير نشان مىدهد اطمينان يذيرى و وِايدارى روان رويكرد

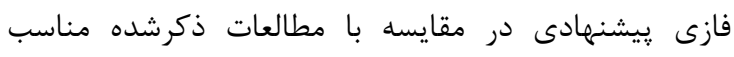

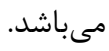
در مطالعه حاضر، نتايج احتمال وقوع بهدست آمده از

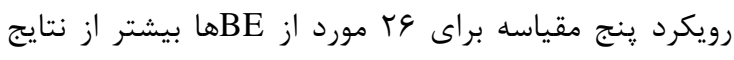

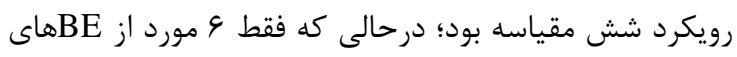

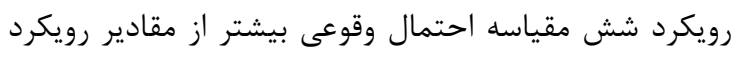

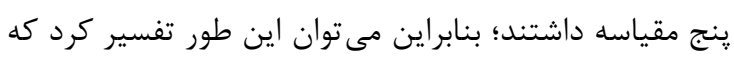

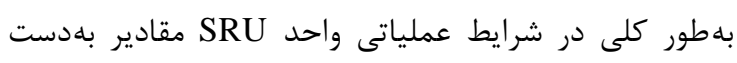

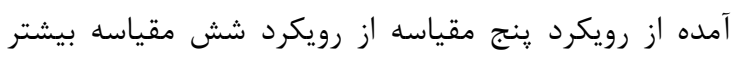

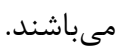

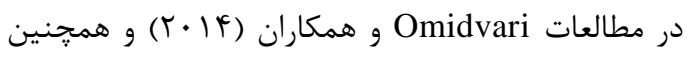

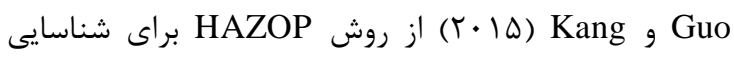

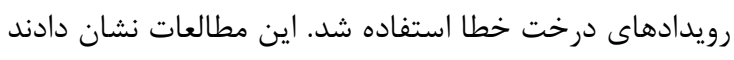
روش HAZOP فرآيندى كه براى ترسيم درخت خطا استفاده

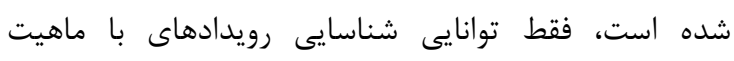


مستقيم توسط خبره با استفاده از امكانهاى وقوع نقص

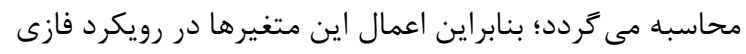
مى تواند دقت مطالعه را افزايش دهائ مهد.

يكى از مشكلات مطالعه حاضر، محدودشدن به استفاده از

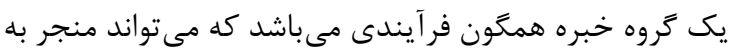
نتايج خوش بينانه گردد. براساس نتايج اين مطالعه و مط مطالعات

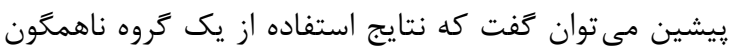

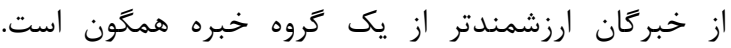

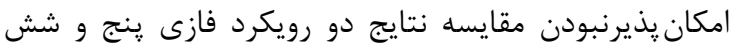

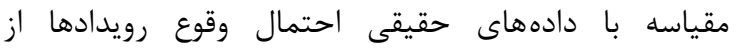

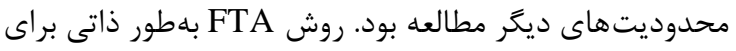

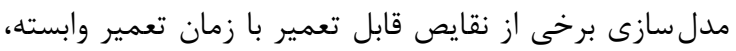

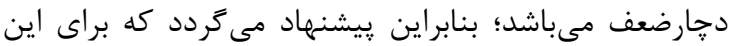

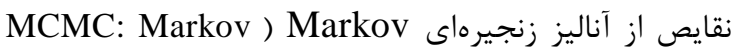
(Chain Monte Carlo استفاده شود. رسير.$$
\text { تشكر و قلروانى }
$$ \\ نويسندكان اين مطالعه از همكارى مسئولان محترم دانشكده

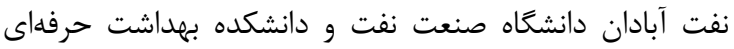 دانشعاه علوم :زشكى جنى جندى شايور اهواز تشكر و قدردانى ويزه} مىنمايند.

\section{REFERENCES}

1. Alaei R, Mansoori SA, Moghaddam AH, Mansoori SM, Mansoori N. Safety assessment approach of hazard and operability (HAZOP) for sulfur recovery unit Claus reaction furnace package; blower; heat exchanger equipment in South Pars gas processing plant. J Natl Gas Sci Eng. 2014;20:27184. DOI: 10.1016/j.jngse.2014.07.007

2. Mokhatab S, Poe WA. Handbook of natural gas transmission and processing. Burlington: Gulf Professional Publishing; 2006.

3. Bedford T, Cooke R. Probabilistic risk analysis: foundations and methods. Cambridge: Cambridge University Press; 2001.

4. Ericson CA. Hazard analysis techniques for system safety. Hoboken, NJ: John Wiley \& Sons; 2005.

5. Guo L, Kang J. An extended HAZOP analysis approach with dynamic fault tree. J Loss Prev Proc Indust. 2015;38:224-32. DOI: $10.1016 /$ j.jlp.2015.10.003

6. SINTEF. OREDA: Offshore reliability data handbook. $4^{\text {th }}$ ed. Trondheim: OREDA Participants; 2002.

7. Less FP. Loss prevention in the process industries: hazard identification, assessment and control. $3^{\text {rd }}$ ed. Burlington: Elsevier Butterworth-Heinemann; 2005.

8. Center for Chemical Process Safety (CCPS). Guidelines for process equipment reliability data with data tables. New York: American Institute of Chemical Engineers (AIChE); 1989.

9. Norwegian Oil Industry Association. Application of IEC 61508 and IEC 61511 in the Norwegian Petroleum Industry. Norway: The Norwegian Oil Industry Association; 2004.

10. Jozi SA, Esmat Saatloo SJ, Javan Z. Environmental risk assessment of the olefin plant in Arya Sasol petrochemical complex using fault tree analysis method. Iran J Health Environt. 2014;7(3):385-98. [Persian]

11. Khosravirad F, Zarei E, Mohammadfam I, Shoja E, Majidi Daryani M. Explosion risk analysis on Town Border Stations (TBS) of natural gas using Failure Mode \& Effect Analysis (FMEA) and Fault Tree Analyses (FTA) methods. Iran Occup Health. 2016;12(6):16-27. [Persian]

12. Mohammad Fam I, Kalatpour O. Risk assessment of liquefied

$$
\begin{aligned}
& \text { اصلى استفاده از رويكرد فازى اين است كه نظرات كيفى خبر گان } \\
& \text { در قالب امكانهاى وقوع نقص مىتواند بهطور مستقيم در } \\
& \text { محاسبه احتمال وقوع رويدادها مورد استفاده قرار گيرد. } \\
& \text { بعد از مصاحبه با خبركان و از نظر عملى، بهمنظور كاهش } \\
& \text { احتمال وقوع MCS بحرانى (Blower C-1)، هم/افزونگى } \\
& \text { (Standby) نوع آماده بيه كار (Redundancy) } \\
& \text { گرديد. نكته اساسى در مورد استفاده از اصل همافزونكى توجه } \\
& \text { به مسائلى همجون وقوع نقايص علل مشترك (CCFs)، آناليز } \\
& \text { هزينه- سود و نحوه تغيير وضعيت بين جزء فعال و آماده به كار } \\
& \text { مى باشد. همجنين براساس نتايج مطالعه حاضر، يك برنامه } \\
& \text { بازرسى - تعمير دقيق براى اجزاى بحرانى شناختهشده همجون }
\end{aligned}
$$

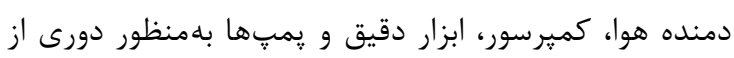

$$
\begin{aligned}
& \text { وقوع نقايص آشكارنشده ييشنـهاد گرديد. } \\
& \text { يكى از مهرمترين نكات بهدست آمده از اين مطالعه و }
\end{aligned}
$$

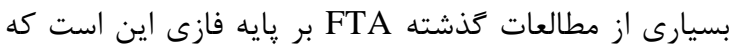

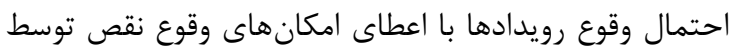

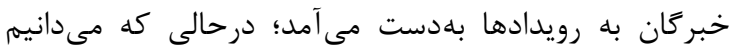

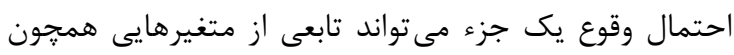

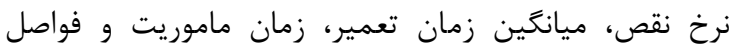

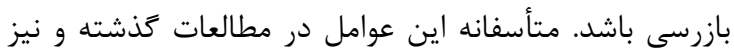

$$
\begin{aligned}
& \text { مطالعه حاضر درنظر كرفته نشدهاند و احتمال وقوع جز بهاطور }
\end{aligned}
$$

petroleum gas (LPG) storage tanks in the process industries using the Bowtie technique. J Occup Hygiene Eng. 2016;3(2):1-11. [Persian]

13. Purba JH, Tjahyani DS, Ekariansyah AS, Tjahjono H. Fuzzy probability based fault tree analysis to propagate and quantify epistemic uncertainty. Ann Nucl Energy. 2015; 85:1189-99. DOI: 10.1016/j.anucene.2015.08.002

14. Zadeh LA. Fuzzy sets. Inform control. 1965;8(3):338-53. DOI:10.1016/S0019-9958(65)90241-X

15. Renjith VR, Madhu G, Nayagam VL, Bhasi AB. Twodimensional fuzzy fault tree analysis for chlorine release from a chlor-alkali industry using expert elicitation. J Hazard Mater. 2010;183(1):103-10. DOI:org/10.1016/j.jhazmat. 2010.06.116

16. Rajakarunakaran S, Kumar AM, Prabhu VA. Applications of fuzzy faulty tree analysis and expert elicitation for evaluation of risks in LPG refuelling station. J Loss Prev Proc Indust. 2015;33:109-23. DOI: 10.1016/j.jlp.2014.11.016

17. Cooke RM, ElSaadany S, Huang X. On the performance of social network and likelihood-based expert weighting schemes. Reliabil Eng Sys Saf. 2008;93(5):745-56. DOI: 10.1016/i.ress.2007.03.017

18. Sa'idi E, Anvaripour B, Jaderi F, Nabhani N. Fuzzy risk modeling of process operations in the oil and gas refineries. $J$ Loss Prev Proc Indust. 2014;30:63-73. DOI: 10.1016/ j.jlp.2014.04.002

19. Miller GA. The magical number seven, plus or minus two: some limits on our capacity for processing information. Psychol Rev. 1956;63(2):81-97.

20. Mokhtari K, Ren J, Roberts C, Wang J. Application of a generic bow-tie based risk analysis framework on risk management of sea ports and offshore terminals. $J$ Hazard Materials. 2011;192(2):465-75. DOI: 10.1016/ j.jhazmat.2011.05.035

21. Chen SJ, Hwang CL. Fuzzy multiple attribute decision making: methods and applications. Berlin: Springer-Verlag; 1992.

22. Onisawa T. An approach to human reliability in man-machine 
systems using error possibility. Fuzzy Sets Sys. 1988;27(2):87-103. DOI:10.1016/0165-0114(88)90140-6

23. Omidvari M, Lavasani SM, Mirza S. Presenting of failure probability assessment pattern by FTA in Fuzzy logic (case study: distillation tower unit of oil refinery process). $J$ Chem Health Saf. 2014;21(6):14-22. DOI: 10.1016/ i.jchas.2014.06.003 